\title{
A STRANGULATED TRANS MESENTERIC HERNIA- AN UNUSUAL CASE OF ACUTE ABDOMEN
}

\author{
Amit Pnadnis ${ }^{1}$
}

${ }^{1}$ Associate Professor, Department of General Surgery, Terna Medical College, Navi Mumbai, Maharashtra, India.

HOW TO CITE THIS ARTICLE: Pnadnis A. A strangulated trans mesenteric hernia- an unusual case of acute abdomen. J. Evolution Med. Dent. Sci. 2018;7(28):3257-3258, DOI: $10.14260 /$ jemds/2018/732

\section{PRESENTATION OF CASE}

A 21-year-old boy presented with pain in abdomen associated with abdominal distension and vomiting since 2-3 days. On systemic examination, the vital parameters were normal. On per abdominal examination, he had generalised distension and mild tenderness in the umbilical region. The bowel sounds were sluggish. On admission, the patient was kept nil by mouth, nasogastric tube was inserted, and intravenous antibiotics and fluids were administered. All routine biochemical investigations sent were normal.

An internal hernia is defined as protrusion of a viscus through a normal or abnormal opening within the boundaries of peritoneal cavity.[1] It is reported that $0.2-0.9 \%$ of patients of small bowel obstruction have internal hernia.[2] Internal hernias are a rare cause of intestinal obstruction with paraduodenal hernias being the most common type of congenital internal hernias.[2]

Trans mesenteric type of hernias constitute $5 \%$ to $8 \%$ of cases of internal hernias.[3] Despite congenital origin, an asymptomatic congenital internal hernia can be diagnosed in adulthood. Mesenteric defect can present with intestinal obstruction and cause incarceration or strangulation. ${ }^{[4]}$ Therefore, a high degree of suspicion is required to lead to early surgical intervention in these cases to reduce morbidity and mortality.[5]

\begin{tabular}{|lc|}
\hline $\begin{array}{l}\text { Table } 1 \\
\text { Laboratory parameters }\end{array}$ \\
\hline Laboratory parameter & \multicolumn{1}{|c|}{ Result } \\
\hline Hemoglobin & $11 \mathrm{~g} / \mathrm{dL}$ \\
WBCs & $11600 / \mathrm{cc}$ \\
BUN & $11 \mathrm{mg} / \mathrm{dL}$ \\
S. Creatinine & $0.9 \mathrm{mg} / \mathrm{dL}$ \\
S. Sodium & $132 \mathrm{mEq} / \mathrm{dL}$ \\
S. Potassium & $3.2 \mathrm{mEq} / \mathrm{dL}$ \\
S. Amylase & $70 \mathrm{lU} / \mathrm{dL}$ \\
\hline
\end{tabular}

'Financial or Other Competing Interest': None. Submission 10-03-2018, Peer Review 06-05-2018,

Acceptance 12-05-2018, Published 09-07-2018.

Corresponding Author:

Amit Pnadnis,

Associate Professor,

Department of General Surgery,

Terna Medical College,

Navi Mumbai, Maharashtra.

E-mail: krantiphadins@gmail.com

DOI: $10.14260 /$ jemds $/ 2018 / 732$

\section{(c) $(1) \subseteq$}

X-ray of abdomen showed picture of subacute small bowel obstruction. An ultrasonography was done, which showed dilated small bowel loops with mild free fluid in the abdomen. Even after conservative management patient was not settled and hence a CT scan of abdomen was done, which showed terminal ileal stricture with free fluid in the abdomen with dilated proximal loops. Patient was taken up for exploratory laparotomy under general anaesthesia with the diagnosis of small bowel obstruction.

\section{Findings in Situ}

A loop of ileum around $20 \mathrm{cms}$ in length had herniated into a mesenteric defect, which was almost $10 \times 10 \mathrm{cms}$ and had undergone gangrenous changes with perforation of the loop, an unusual type of small bowel obstruction due to internal hernia.

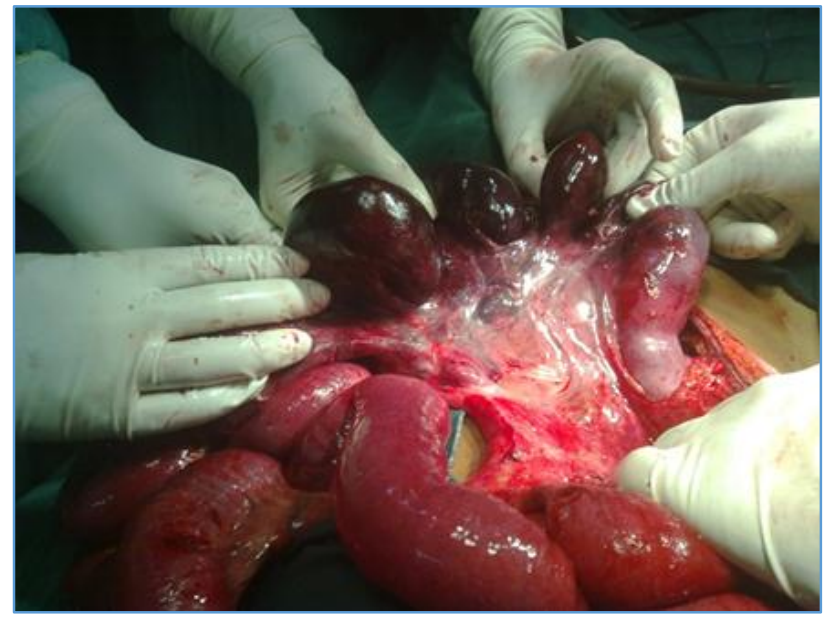

Figure1. Gangrenous herniated loop of small intestine

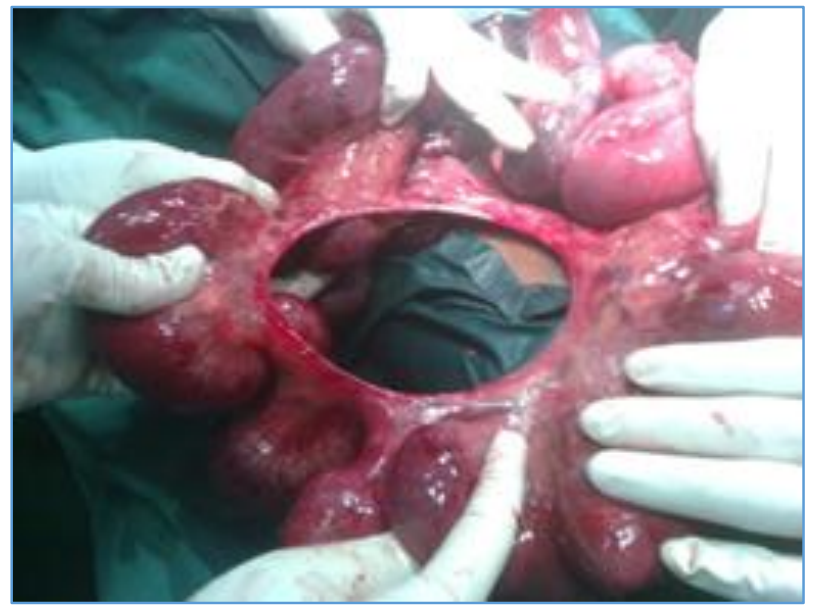

Figure 2. Congenital Rent of $10 * 10 \mathrm{~cm}$ size in the small Bowel Mesentery

The herniated loop was removed, ileo-ileal resection anastomosis was done after excision of the affected part with clear margins. The circular defect in the small bowel 
mesentery was closed, drain was kept and closure was done. Patient recovered over a period of one week, was comfortable and ambulatory and was discharged on day 10 .

\section{DIFFERENTIAL DIAGNOSES \\ Intestinal Obstruction due to- \\ a. Internal mesenteric hernia. \\ b. Mesenteric ischaemia. \\ c. Bands/ Adhesions.}

\section{CLINICAL DIAGNOSIS}

Intestinal obstruction due to internal hernia.

\section{PATHOLOGICAL DISCUSSION}

Congenital trans mesenteric internal hernia is a rare condition presenting as recurrent pain abdomen or acute intestinal obstruction.[6] Internal hernias account for about 0.2 to $0.8 \%$ of the cases. Trans mesenteric hernias are even rarer constituting $5 \%$ to $10 \%$ of causes of internal hernia. [7] Nearly, $35 \%$ of trans mesenteric hernia manifests in the paediatric age group, in which they constitute the most common type of internal hernia. Hensing in 1742 was the first to describe surgical anatomy of some varieties of internal hernia.

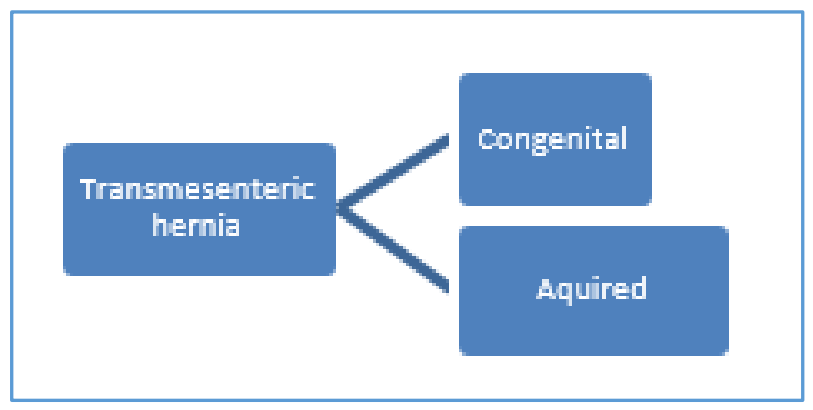

Congenital mesenteric defects often occur in small bowel mesentery and less commonly in colonic mesentery.

Acquired internal hernias are due to surgical manipulation of the bowel and mesentery or following blunt abdominal trauma. The common location of mesenteric defects is in the region of small bowel ( $70 \%$ of cases) with $53 \%$ of these being in the ileocaecal region of mesentery.

Due to rarity of the case, diagnosis of internal hernia remains a challenge for both clinician and radiologist.[8] The symptoms of internal hernias are non-specific ranging from mild abdominal discomfort or nausea alternating with cramps,[2] because of which preoperative diagnosis is often missed. The plain radiographs of the abdomen show mechanical small bowel obstruction. Small bowel examination may disclose a constriction around the closely approximated afferent and efferent limbs of the herniated intestine. CT scan of the abdomen shows cluster of dilated bowel loops lying adjacent to the bowel wall without overlying omental fat with central displacement of adjacent colon.

\section{DISCUSSION OF MANAGEMENT}

The management of internal hernias requires early surgical intervention to prevent morbidity and other complications. In these cases, there is high incidence of bowel ischaemia and gangrene and usually, laparotomy for resection of the strangulated loop of bowel is required. In closing the defect, care must be taken to avoid injuring the vessels near the margins of the defect.

\section{FINAL DIAGNOSIS}

Intestinal Obstruction due to Internal Mesenteric Hernia.

\section{CONCLUSION}

Preoperative diagnosis of internal hernia is very rare.[6] Early intervention and surgical correction goes a long way in preventing high morbidity and mortality.

This case highlights a rare cause of intestinal obstruction in patients with no previous abdominal surgery. Severe unexplained abdominal pain in adults can be due to trans mesenteric hernia. Diagnosis requires high index of suspicion and early surgical exploration to avoid morbidity. Nowadays, with widespread use of laparoscopic surgery, internal hernias may become an increasing surgical problem. In case of small bowel obstruction without past abdominal surgery, possibility of internal hernia should be considered.

\section{REFERENCES}

[1] Blachar A, Federle MP, Dodson SF. Internal hernia: clinical and imaging findings in 17 patients with emphasis on CT criteria. Radiology 2001;218(1):68-74.

[2] Fan HP, Yang AD, Chang YJ, et al. Clinical spectrum of internal hernia: a surgical emergency. Surg Today 2008;38(10):899-904.

[3] Akyildiz H, Artis T, Sozuer E, et al. Internal hernia: complex diagnostic and therapeutic problem. Int J Surg 2009;7(4):334-7.

[4] Katagiri H, Okumura K, Machi J. Internal hernia due to mesenteric defect. J Surg Case Rep 2013;2013(5):rjt037.

https://doi.org/10.1093/jscr/rjt03708 May 2013.

[5] Elenin HH, Khan M, Harikrischnan A. Strangulated internal hernia: a case report. OA Case Reports 2014;3(3):29.

[6] Vallumsetla R, Rao GN. Congenital transmesenteric internal hernia - a case report with literature review. Indian J Surg 2010;72(3):268-70.

[7] Kar S, Mohapatra V, Rath PK. Rare type of primary internal hernia causing small intestinal obstruction. Article ID 3540794, Case Reports in Surgery 2016;(2016):3.

http://dx.doi.org/10.1155/2016/3540794

[8] Martin LC, Merkle EM, Thompson WM. Review of internal hernias: radiographic and clinical findings. AJR Am J Roentgenol 2006;186(3):703-17. 